\title{
Psychometric properties of a German version of the neck pain and disability scale
}

\author{
Martin Scherer · Eva Blozik · Wolfgang Himmel · \\ Daria Laptinskaya $\cdot$ Michael M. Kochen • \\ Christoph Herrmann-Lingen
}

Received: 6 December 2007 /Revised: 12 March 2008/Accepted: 8 April 2008/Published online: 25 April 2008

(C) The Author(s) 2008

\begin{abstract}
The aim of this study is to evaluate the validity and the psychometric properties of a German version of the 20-item neck pain and disability scale (NPAD) for use in primary care settings. Four hundred and forty-eight participants from 15 general practices in the area of Göttingen Germany completed a multidimensional questionnaire including a newly developed German version of the NPAD (NPAD-d) and self-reported demographic and clinical information. Reliability was tested using Cronbach's alpha. Item-to-total score correlations were analysed. Factor structure was explored by using unrestricted principal factor analysis. Construct validity of the NPAD-d was evaluated by simple correlation analyses (Pearson's rho) with social and clinical characteristics. The discriminative abilities of the NPAD-d were examined by comparing differences between subgroups stratified on non-NPAD-d pain related characteristics using $t$ tests for mean scores. Cronbach's alpha of NPAD-d was 0.94. Item-to-total scale correlations ranged between 0.414 and 0.829 . Exploratory principal factor analysis indicated that the NPAD-d covers one factor with an explained variance of $48 \%$. Correlation analysis showed high correlations with criterion variables. The NAPD-d scores of subgroups of patients were
\end{abstract}

Martin Scherer and Eva Blozik are equal contributors.

M. Scherer · E. Blozik ( $\square)$ - W. Himmel · D. Laptinskaya ·

M. M. Kochen

Department of General Practice and Family Medicine,

Georg-August-University of Göttingen,

Humboldtallee 38, 37073 Göttingen, Germany

e-mail: eblozik@gwdg.de

C. Herrmann-Lingen

Department of Psychosomatic Medicine and Psychotherapy,

University of Göttingen, von-Siebold-Str. 5,

37075 Göttingen, Germany significantly different showing good discriminative validity of the scale. The NPAD-d demonstrated good validity and reliability in this general practice setting. The NPAD-d may be useful in the clinical assessment process and the management of neck pain.

Keywords Neck pain - Assessment - General practice · Validity $\cdot$ Reliability

\section{Introduction}

Neck pain is a highly prevalent condition with about two thirds of the adult population affected at some time in their lives [6]. Unspecific neck pain usually resolves within days, but in $10 \%$ neck pain recurs or becomes chronic. Quantification of neck pain is necessary not only for the evaluation of current and future therapies, but also for assessing clinical outcomes of impairment and disability [2]. Although several measures of generalised pain and disability were available (i.e. Oswestry Disability Questionnaire and Pain Disability Index) [13], there was no well-developed measure that dealt specifically with neck pain until 1999.

In order to provide a new comprehensive measure of neck pain and disability the neck pain and disability scale (NPAD) has been developed by Wheeler and colleagues specifically to be used in this condition [15]. The NPAD measures problems with neck movements, neck pain intensity, effect of neck pain on emotion and cognition, and the level of interference in daily life activities. The NPAD has been found easy to complete for patients and simple to score, and it provides a validated measure to evaluate outcomes in patients with neck pain [9, 15]. Originally developed in the USA to date, validated French [16], 
Portuguese [5], and Turkish [2] translations are available showing adequate validity and reliability. The NPAD has been regularly used in previous studies [11].

The aim of this study was to develop a German version of the NAPD (NPAD-d) and evaluate its internal consistency as well as its construct and discriminant validity in a primary care setting.

\section{Methods}

\section{Study design}

This was a cross-sectional survey including patients from a GP setting in Germany with at least one onset of neck pain between March 2005 and April 2006. The study was approved by the local research ethics committee.

\section{Instruments}

Participants received a comprehensive self-administered questionnaire covering multiple domains such as sociodemographic information, anxiety, depression, social support, and neck pain. Participants received the questionnaire from primary care physicians together with written instructions. Due to budgetary constraints no mail or telephone follow-up was done when persons did not or incompletely return the questionnaire.

Neck and pain disability scale $[9,15]$

The NPAD is a 20 -item measure that was specifically developed for patients with neck pain. It measures the intensity of pain; its interference with vocational, recreational, social, and functional aspects of living; and the extent of associated emotional factors. Patients responded to each item by marking along a $10 \mathrm{~cm}$ visual analogue scale. Item scores range from 0 to 5 , and the total score (possible range 0-100) is the sum of the item scores. A valid NPAD score can be generated if no more than $15 \%$ of the items are missing. The NPAD has been shown to have validity in comparison to other self-reported pain measures [9] as well as supporting constructs of mood and neuroticism [15]. Previous studies have shown that NPAD items clustered into three $[5,16]$ or four to five [9] subscales.

Development of the neck and pain disability scale German version

Originally developed in an Anglo-American context, the rather simply worded NAPD was culturally adapted and translated into German. Two authors (MS, WH) independently translated the original version with the help of an
English native speaker and critically reviewed translation versions reciprocally. All authors in the group resolved disagreements if any through discussion. Due to the simple wording of questionnaire and the unitary structure of the questions we abstained from back translation of the questionnaire (Appendix 1). According to the original version, item scores range from 0 to 5 , and the total score (possible range $0-100$ ) is the sum of the item scores.

Hospital anxiety and depression scale [3, 10, 17]

The hospital anxiety and depression scale (HADS) is a widely used short self-assessment questionnaire, especially developed for physically ill patients. Its items mainly ask for psychological manifestations of (generalised) anxiety and depressive mood. Each of the two subscales consists of seven items. Possible subscale scores range from 0 to 21 .

Social support questionnaire [8]

The 14-item short form (five-point scale from "relevant" to "not relevant") assesses perceived social support (F-SozU). The items refer to different aspects of experienced support (emotional support, instrumental support and social integration), resulting in a global scale with higher scores indicating better social support.

The German versions of the HADS and the FSozU have been previously validated and were considered to be suitable for research in physically ill patients $[3,8,10,17]$.

\section{Recruitment of patients}

As part of a project on the quality of medical care in general practice (MedViP), a network of 104 general practices has been established [14]. Fifteen of these within a radius of $30 \mathrm{~km}$ around Göttingen were selected for participation and provided anonymised electronic patient data (date of birth, sex, diagnosis). Patients were included in a list of potentially eligible persons if at least one consultation because of neck pain was documented in the electronic patient record during the period from March 2005 to April 2006. All GPs were asked to exclude patients from a list of 1,308 potentially eligible persons, if they had their neck pain consultation because of a new trauma, were terminally ill, suffered from cancer, were in need of nursing care or had severe cognitive impairment. Additionally, patients seen by locums only, patients who had moved to a region outside of the study area or who were not able to speak German were excluded from the study. Eighty persons did not fulfil the inclusion criteria; 1,228 persons were invited to participate in the study. Of those, 745 were not willing to participate in the study. In fact, 483 persons gave their informed consent to participate and received the 
comprehensive questionnaire. Of those, 22 (5\%) did not return or complete the questionnaire. In 13 of 461 persons with completed questionnaires (3\%), no NPAD-d score was available because those persons had more than three NPAD-d items missing. The final analytic sample consisted of 448 persons with a valid NPAD-d score (Fig. 1).

\section{Statistical analyses}

First, summary statistics including simple counts, percentages, and mean values were computed to describe the demographic and health-related characteristics of the samples. Then NPAD-d total scores were calculated as previously described using the same method as the original NPAD. Up to three missing item values were imputed by value substitution based on each subject's valid responses to NPAD-d items. Specifically, imputed values for missing
NPAD items were calculated by dividing the sum of the non-missing NPAD-d items by the number of the nonmissing items.

The descriptive properties of the normally distributed NPAD-d were evaluated using frequency distributions, percentages, and mean values. Internal consistency of the NPAD-d was examined using Cronbach's alpha. The range of coefficient alpha $(\alpha)$ values is generally categorised as $0.60-0.64$ minimally acceptable, $0.65-0.70$ acceptable, $0.70-0.74$ good, $0.75-0.80$ very good, and 0.80 and above excellent [7]. Then, standardised item-to-total score correlations were analysed by calculating correlation coefficients between each item and the sum of all other NPAD-d items excluding the item investigated. Factor structure was explored using unrestricted principal factor analysis and unrestricted principal component analysis with varimax rotation. Eigenvalues greater than 1.0 were
Fig. 1 Flowchart of participants
1308 consulted general practitioner because of neck pain in previous 12 months

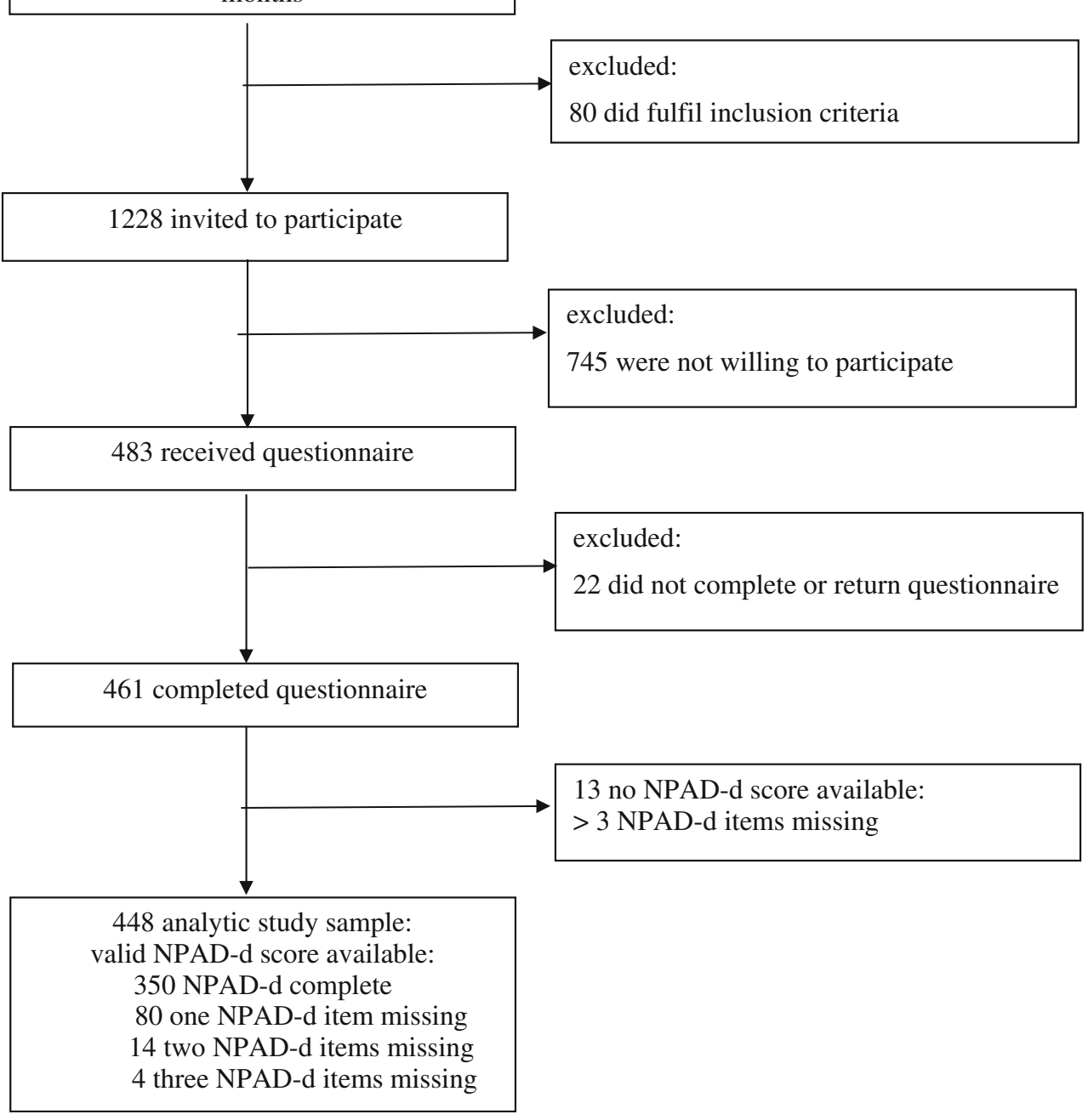


used to identify clustering of items. The factor structure was determined by attributing any items that had factor loadings $>0.5$ to a specific factor.

Construct validity of the NPAD-d was explored using simple correlations of the NPAD-d with constructs known to be associated with neck pain (HADS depression subscale, HADS anxiety subscale, FSozU social support scale, number of visits with GPs, orthopaedists, and anaesthetists respectively) and with non-NAPD-d neck pain related characteristics (number of days with neck pain in previous year) using Pearson's rho coefficients (convergent validity) [4, 12]. Using $t$ tests for mean scores, the discriminative abilities of the NPAD-d were examined by comparing differences between subgroups stratified on psychological characteristics known to be associated with neck pain $[2,16]$ (depression according to HADS depression subscale, anxiety according to HADS anxiety subscale) and non-NPAD-d neck pain related characteristics (neck pain on the day of questionnaire completion).

All $P$ values reported were two-sided and all analyses were performed using Stata 9.2 (Stata Corporation, College Station, TX/USA).

\section{Results}

Demographic and clinical characteristics of the study sample

Of the 448 patients included in the analysis, $56 \%$ reported to have neck pain on the day of questionnaire completion. Mean age was $49 \pm 16$ years. Almost $80 \%$ of the study participants were female. One third had basic education, and about one third were unemployed or retired. The mean value of the HADS depression subscale (range 0-21) was $5.4 \pm 3.8$. The mean HADS anxiety subscale (range 0-21) was $8.0 \pm 4.1$. In the study population perceived social support was generally high with a mean social support score (range 1-5) of $4.2 \pm 0.7$ (Table 1).

Descriptive analysis of the neck and pain disability scale German version

Ranging from 0 to 100 , mean NPAD-d was $48.6 \pm 18.6$ (Table 1). Of the 448 persons included in the analyses, 350 (78\%) had no missing NPAD-d items, 80 persons (18\%) had one missing item, 14 persons (3\%) had two missing items, and four persons $(<1 \%)$ had three missing items. The frequency of missing items was evenly distributed in the NPAD-d items with the exception of items \#7 (pain while driving or riding a car) and \#20 (effect of pain pills).
Table 1 Demographic and clinical characteristics of the sample $(n=448)$

\begin{tabular}{lll}
\hline Baseline variables & $N(\%)$ & Mean (SD) \\
\hline Neck pain & $246(55.5)$ & \\
Neck pain today & \multicolumn{2}{c}{$49.4(15.5)$} \\
Sociodemographic parameters & $350(78.1)$ \\
Age (years) & $340(76.1)$ & \\
Female & $152(33.9)$ & \\
Living with a partner & $165(36.8)$ & \\
Basic education (<10 years at school) & & \\
Unemployed or retired & & $5.4(3.8)$ \\
Psychometric characteristics & & \\
Depression (HADS depression subscale) & & $(4.1)$ \\
$(0-21)^{\mathrm{a}}$ & & $4.2(0.7)$ \\
Anxiety (HADS anxiety subscale) (0-21) & & \\
Social support (FSozU) (1-5) & & \\
Neck pain and disability scale German & & \\
version (NPAD-d) (0-100) & & \\
\hline
\end{tabular}

\footnotetext{
a $H A D S$ hospital anxiety and depression scale

b FSozU Fragebogen zur sozialen Unterstützung (Social Support Questionnaire)
}

Those questions had a notably higher number of missing items, probably because some of the patients didn't drive or take pain pills, respectively.

Psychometric properties of the neck and pain disability scale German version

Cronbach's alpha of NPAD-d was 0.94 denoting excellent internal consistency of the scale. The item to total correlation of the individual NPAD-d items with the total scale ranged from 0.461 to 0.817 showing consistently significant correlations of the single items with the total scale (Table 2).

Exploratory principal component analysis indicated that the NPAD-d items rather uniformly load on a single factor. The only exception was item \#1 which had a borderline loading of 0.414 on the single factor, which explained $48 \%$ of the variance (Table 3, left column).

Using the Eigenvalue criterion, three factors as compared to one factor were retained. However, the two additional factors only led to a moderate improvement in explained variance as each of them explained only $6 \%$ of the NPAD-d variance in the unrotated model. In the threefactor model, 19 of the 20 NPAD-d items could be attributed to at least one factor or had borderline factor loadings of between 0.4 and 0.5 . Only item \#20 (effect of pain pills) failed to load on any of the three factors. Cross-loadings or non-loading of items was not uncommon. Several items seemed to measure more than one construct because they 
Table 2 Item to total score correlations of NPAD-d items $(N=448)$

\begin{tabular}{|c|c|c|}
\hline Item-Nr. NPAD-d ${ }^{a}$ & Dimension & \\
\hline 1 & $\begin{array}{l}\text { Pain at day of questionnaire } \\
\text { completion }\end{array}$ & 0.461 \\
\hline 2 & Pain on average & 0.661 \\
\hline 3 & Pain at its worst & 0.618 \\
\hline 4 & Sleeping & 0.668 \\
\hline 5 & Standing & 0.715 \\
\hline 6 & Walking & 0.727 \\
\hline 7 & Driving & 0.677 \\
\hline 8 & Social activities & 0.817 \\
\hline 9 & Recreational activities & 0.732 \\
\hline 10 & Working & 0.749 \\
\hline 11 & Personal care & 0.724 \\
\hline 12 & Relationships & 0.773 \\
\hline 13 & Outlook on life and future & 0.738 \\
\hline 14 & Emotions & 0.715 \\
\hline 15 & Thinking/concentration & 0.683 \\
\hline 16 & Stiffness & 0.681 \\
\hline 17 & Turning the neck & 0.710 \\
\hline 18 & Looking up or down & 0.721 \\
\hline 19 & Working overhead & 0.669 \\
\hline 20 & Effect of pain pills & 0.568 \\
\hline
\end{tabular}

${ }^{a}$ NPAD-d neck pain and disability scale German version

tended to load on more than one factor (items \# 8-11, 13) (Table 3, right column).

\section{Construct validity}

Correlation analysis showed highly significant correlations with criterion variables. Specifically, measures of depression (HADS depression subscale: Pearson's rho $=0.436$, $P<0.001$ ), anxiety (HADS anxiety subscale: Pearson's rho $=0.410, P<0.001$ ), and social support (FSozU: Pearson's rho $=-0.168, P<0.001$ ) were highly correlated with NPAD-d values. Number of days with neck pain in the previous year, a non-NPAD-d neck pain related characteristic, showed also a strong correlation with NPAD$\mathrm{d}$ (Pearson's rho $=0.363, P<0.001)$. Additionally, measures of health care use (number of visits with a GP: Pearson's rho $=0.246, P<0.001$; number of visits with an orthopaedist: Pearson's rho $=0.213, P=0.026$; number of visits with an anaesthetist: Pearson's rho $=0.597$, $P=0.015)$ were relevantly correlated with NPAD-d.

\section{Discriminative validity}

An analysis of the NAPD-d and its ability to discriminate between subgroups of patients with different neck pain-
Table 3 Factor structure of the NPAD-d (unrotated 1-factor solution and varimax rotation of 3-factor solution)

\begin{tabular}{|c|c|c|c|c|}
\hline \multirow{2}{*}{$\begin{array}{l}\text { Item-Nr. } \\
\text { NPAD-d }\end{array}$} & \multirow{2}{*}{$\begin{array}{l}\text { Unrotated 1-factor } \\
\text { solution } \\
\text { Factor } 1\end{array}$} & \multicolumn{3}{|c|}{ Varimax rotation of 3-factor solutio } \\
\hline & & Factor 1 & Factor 2 & Factor 3 \\
\hline 1 & 0.414 & 0.385 & 0.404 & 0.030 \\
\hline 2 & 0.660 & 0.729 & 0.231 & -0.178 \\
\hline 3 & 0.610 & 0.643 & 0.179 & -0.236 \\
\hline 4 & 0.643 & 0.558 & 0.310 & -0.268 \\
\hline 5 & 0.727 & 0.746 & 0.257 & -0.224 \\
\hline 6 & 0.741 & 0.739 & 0.253 & -0.259 \\
\hline 7 & 0.657 & 0.496 & 0.337 & -0.337 \\
\hline 8 & 0.829 & 0.605 & 0.260 & -0.556 \\
\hline 9 & 0.725 & 0.612 & 0.139 & -0.493 \\
\hline 10 & 0.745 & 0.576 & 0.252 & -0.465 \\
\hline 11 & 0.714 & 0.478 & 0.407 & -0.381 \\
\hline 12 & 0.763 & 0.319 & 0.250 & -0.768 \\
\hline 13 & 0.709 & 0.212 & 0.401 & -0.657 \\
\hline 14 & 0.695 & 0.165 & 0.230 & -0.838 \\
\hline 15 & 0.669 & 0.231 & 0.190 & -0.766 \\
\hline 16 & 0.658 & 0.159 & 0.778 & -0.282 \\
\hline 17 & 0.700 & 0.231 & 0.823 & -0.226 \\
\hline 18 & 0.699 & 0.243 & 0.809 & -0.235 \\
\hline 19 & 0.634 & 0.274 & 0.584 & -0.312 \\
\hline 20 & 0.538 & 0.318 & 0.324 & -0.343 \\
\hline
\end{tabular}

In bold: attributed to the factor (factor loading $\geq 0.5$ )

In italic: borderline factor loading $(0.4>$ factor loading $>0.5)$

${ }^{a}$ NPAD-d neck pain and disability scale German version

related characteristics are shown in Table 4. Based on depression symptoms, anxiety symptoms, as well as presence of neck pain on the day of questionnaire completion the NPAD-d distinguished between these groups with a high level of significance.

\section{Discussion}

This newly developed German version of the neck pain and disability scale (NPAD-d) demonstrated good validity and reliability in a general practice setting. The NPAD-d exhibited stable internal consistency, good construct and discriminant validity. It can thus be reliably administered using standard population survey techniques albeit with some uncertainty regarding the factor structure.

This is the first study to develop and validate a German version of the NPAD in a primary care setting. It was conducted in a relatively large group recruited by a defined algorithm from the whole patient population of various practices and is therefore largely representative of the typical neck pain patients seen in general practice. The 
Table 4 Comparison of the NPAD-d across groups with different social and clinical characteristics
${ }^{a}$ NPAD-d neck pain and disability scale German version

${ }^{\mathrm{b}} H A D S$ hospital anxiety and depression scale

\begin{tabular}{|c|c|c|c|c|}
\hline \multicolumn{5}{|c|}{ Depression (according to HADS ${ }^{\mathrm{b}}$ depression subscale) } \\
\hline & Yes & No & $\Delta(95 \% \mathrm{CI})$ & $P$ \\
\hline & $N=86$ & $N=359$ & & \\
\hline NPAD- $d^{a}$ & $60.7 \pm 17.2$ & $45.8 \pm 17.8$ & $14.9(10.7,19.1)$ & $<0.001$ \\
\hline \multicolumn{5}{|c|}{ Anxiety (according to $\mathrm{HADS}^{\mathrm{b}}$ anxiety subscale) } \\
\hline & Yes & No & $\Delta(95 \% \mathrm{CI})$ & $P$ \\
\hline & $N=123$ & $N=322$ & & \\
\hline NPAD- $\mathrm{d}^{\mathrm{a}}$ & $57.3 \pm 18.8$ & $45.3 \pm 17.4$ & $12.0(8.3,15.7)$ & $<0.001$ \\
\hline \multicolumn{5}{|c|}{ Neck pain on the day of questionnaire completion } \\
\hline & Yes & No & $\Delta(95 \% \mathrm{CI})$ & $P$ \\
\hline & $N=246$ & $N=197$ & & \\
\hline NPAD- $\mathrm{d}^{\mathrm{a}}$ & $52.8 \pm 17.3$ & $43.4 \pm 18.6$ & $9.4(6.0,12.7)$ & $<0.001$ \\
\hline
\end{tabular}

quite large number of exclusions can be traced back to predefined reasons according to this algorithm (Fig. 1) so that it seems unlikely that our sample was subject to an unintentional selection bias.

There are several limitations to consider in evaluating this research. First, the population consisted largely of subjects with mild or moderate neck pain indicated by mean NPAD-d scores of 48.6. Although this may be expected in this adult population, the NPAD-d should also be tested in populations with severe pain and/or disability. Second, although the NPAD compared favourably to other pain measures in a previous study [9], no comparisons of the German version to other pain instruments were possible in this project. Third, the study data were derived crosssectionally. Therefore, the instrument has not been tested for sensitivity to change, to detect change over time, or for feasibility and utility in clinical settings. It is worth noting that test-retest reliability of the NPAD was estimated to be good in the original publication.

The most precise and reliable evidence of the presence and intensity of pain is the patients' self-report [1]. However, there is no established "gold standard" for pain assessment with which to compare a pain scale for a specific condition. Therefore, comparisons must rely on other constructs known to be associated with pain or other methods of pain assessment. Our study results consistently showed high correlations of the NPAD-d with constructs of mood, anxiety, ambulatory health care utilisation, and nonNPAD-d related pain indicators. These highly desirable measurement properties have previously been demonstrated for the original version of the NPAD and for the French [16], Portuguese [5], and Turkish [2] versions. High internal consistency values, as found in this study for the NPAD-d, have also been reported for the original version [15] and for the other three adapted versions [2, 5, 16].

However, in factor analyses of former studies differing numbers of factors on which NPAD version items were loading have been identified. For the French [16] and the Portuguese [5] versions, NPAD items loaded on three factors, whereas in the original publication NPAD items clustered into four to five [9, 15] subscales, although that publication was based on a relatively small sample and the stability of the observed factor solution may be questioned. In this study, we found slightly differing results in factor analysis. Our model derived from principal factor analysis indicated a one-factor solution for the NPAD-d; when using the Eigenvalue criterion, three factors were retained. However, when comparing the results of the factor analysis of the NPAD as they have been presented in the original publication [15] with the results of our three-factor model, clustering of items showed high concordance. Additionally, several original NPAD items tended to load on more than one factor which is also consistent with our findings. Therefore, due to cross-loading or non-loading of items in this model and due to the small amount of variance explained by two of the three factors retained in the principal factor model, we assume that the single-factor model reflects the content structure of the NPAD-d more robustly. We conclude that the NPAD is a multidimensional assessment instrument measuring different facets of one construct, neck pain, in a stable manner. Additionally, the number of factors identified in the French and Portuguese version studies was also different from the original publication which is further evidence that the factor structure presented in the original publication may be too samplespecific to be reproducible in separate samples.

The NPAD-d is the first self-administered questionnaire for the assessment of neck pain available in German. Cronbach's alpha values of higher than 0.90 may be indicative of redundancy of the scale [7]. Given the high Cronbach's alpha of 0.94 , previous research and our results indicate that it may be possible to shorten the 20-item NPAD-d instrument without losing significant reliability and validity. 
This study provides a first step in furthering knowledge of self-administered neck pain assessment in the Germanspeaking countries and highlights some important concerns with regard to the factor structure and usability of the NPAD. Further studies on the effects of clinical assessment process and the management of neck pain are necessary before widespread use of the NPAD-d in the clinical context.

Acknowledgments The study was supported by the German Ministry of Education and Research (BMBF), Grant Nr. 01 GK 0516. MS is funded by a Young Investigators' Award of the BMBF.

Open Access This article is distributed under the terms of the Creative Commons Attribution Noncommercial License which permits any noncommercial use, distribution, and reproduction in any medium, provided the original author(s) and source are credited.

\section{Appendix 1}

Items of the Neck Pain and Disability Scale German version (NPAD-d).

\footnotetext{
1. Wie stark sind Ihre Nackenschmerzen heute? kein Schmerz | _ $0 \_\mid$

2. Wie stark sind Ihre Nackenschmerzen durchschnittlich?

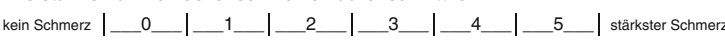

3. Wie schlimm sind die Nackenschmerzen, wenn sie am stärksten sind?

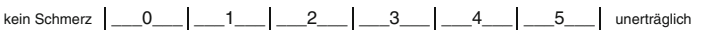

4. Wird Ihr Schlaf von den Nackenschmerzen beeinträchtigt?

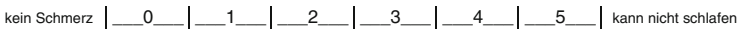

5. Wie stark sind die Nackenschmerzen im Stehen? kein Schmerz I_o_

6. Wie stark sind die Nackenschmerzen im Gehen?

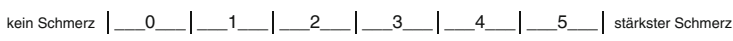

7. Wird das Autofahren durch Ihre Nackenschmerzen beeinträchtigt?

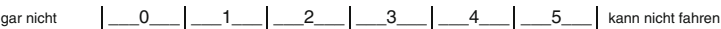

8. Werden Ihre Alltagsaktivitäten durch die Nackenschmerzen beeinträchtigt?

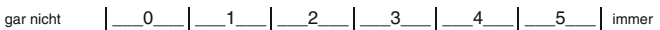

9. Stören Sie die Nackenschmerzen, während Sie sich erholen?

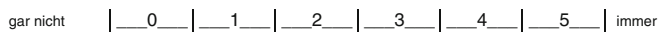

10. Wird Ihre Arbeit durch die Nackenschmerzen beeinflusst?

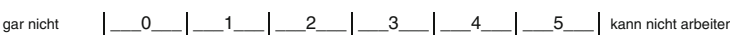

11. Beeinträchtigen Sie Ihre Nackenschmerzen beim Essen oder bei der Körperpflege (Waschen, Ankleiden etc.)?

gar nicht I__ 0 _

12. Werden Ihre persönlichen Beziehungen (Familie, Freunde, Sexualität etc.) durch die Nackenschmerzen beeinträchtigt?

gar nicht $\quad \mid$

13. Wie stark haben die Nackenschmerzen Ihre Lebensperspektiven und Ihre Zukunft verändert?

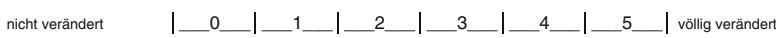

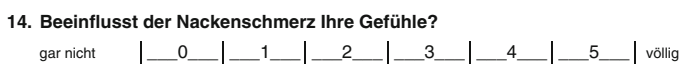

15. Beeinflusst der Nackenschmerz Ihr Denkvermögen oder Ihre Konzentrationsfähigkeit? gar nicht | _ $0 \_$___ $1 \_\mid$

16. Wie steif ist Ihr Nacken?

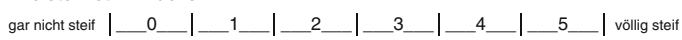

17. Wie stark ist die Beweglichkeit Ihres Kopfes gestört?

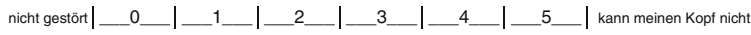
bewegen

18. Wie schwer fällt es Ihnen, den Kopf nach oben oder unten zu richten? gar nicht schwer $\mid$

19. Wie schwer fällt es Ihnen (aufgrund Ihrer Nackenschmerzen) über Kopf zu arbeiten?

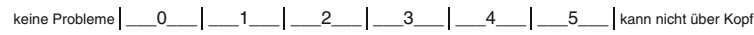
arbeiten

20. Wie gut helfen Ihnen Schmerztabletten gegen Ihre Nackenschmerzen? völlige Schmerzfreiheit | _ $0 \_$_

\section{References}

1. AGS Panel on chronic pain in older person (2002) The management of persistent pain in older persons. J Am Geriatr Soc 50:S205-S224

2 Bicer A, Yazici A, Camdeviren H, Erdogan C (2004) Assessment of pain and disability in patients with chronic neck pain: reliability and construct validity of the Turkish version of the neck pain and disability scale. Disabil Rehabil 26:959-962

3. Bjelland I, Dahl AA, Haug TT, Neckelmann D (2002) The validity of the hospital anxiety and depression scale-an updated literature review. J Psychosom Res 52:69-77

4. Blozik E, Stuck AE, Niemann S, Ferrell BA, Harari D, von Renteln-Kruse W, Gillmann G, Beck JC, Clough-Gorr KM (2007) Geriatric pain measure short form: development and initial evaluation. J Am Geriatr Soc 55:2045-2050

5. Cook C, Richardson JK, Braga L, Menezes A, Soler X, Kume P, Zaninelli M, Socolows F, Pietrobon R (2006) Cross-cultural adaptation and validation of the Brazilian Portuguese version of the Neck Disability Index and Neck Pain and Disability Scale. Spine 31:1621-1627

6. Cote P, Cassidy D, Carroll L (1998) The Saskatchewan health and back pain survey: the prevalence of neck pain and related disability in Saskatchewan adults. Spine 23:1689-1698

7. DeVellis RF (2003) Scale development: theory and applications. Sage, Newbury Park

8. Frydrich T, Sommer G, Brähler E (2002) F-SozU-Social support questionnaire. In: Brähler E, Schumacher J, Strauß B (eds) Diagnostic instruments in psychotherapy. Hogrefe, Göttingen

9. Goolkasian P, Wheeler AH, Gretz SS (2002) The neck pain and disability scale: test-retest reliability and construct validity. Clin J Pain 18:245-250

10. Herrmann C (1997) International experiences with the hospital anxiety and depression scale-a review of validation data and clinical results. J Psychosom Res 42:17-41

11. Kongsted A, Bendix T, Qerama E, Kasch H, Bach FW, Korsholm L, Jensen TS (2008) Acute stress response and recovery after whiplash injuries. A one-year prospective study. Eur J Pain $12: 455-463$ 
12. Lubben JE (1988) Assessing social networks among elderly populations. Fam Community Health 11:42-52

13. Vernon H, Mior S (1991) The neck disability index: a study of reliability and validity. J Manipulative Physiol Ther 14:409-415

14. Wetzel D, Himmel W, Heidenreich R, Hummers-Pradier E, Kochen MM, Rogausch A, Sigle J, Boeckmann H, Kuehnel S, Niebling W, Scheidt-Nave C (2005) Participation in a quality of care study and consequences for generalizability of general practice research. Fam Pract 22:458-464
15. Wheeler AH, Goolkasian P, Baird AC, Darden BVn (1999) Development of the neck pain and disability scale. Item analysis, face, and criterion-related validity. Spine 24:1290-1294

16. Wlodyka-Demaille S, Poiraudeau S, Fermanian J, Catanzariti JF, Rannou F, Revel M (2001) French translation and validation of a functional disability scale for neck pain. Ann Readapt Med Phys 44:132-142

17. Zigmond AS, Snaith RP (1983) The hospital anxiety and depression scale. Acta Psychiatr Scand 67:361-370 